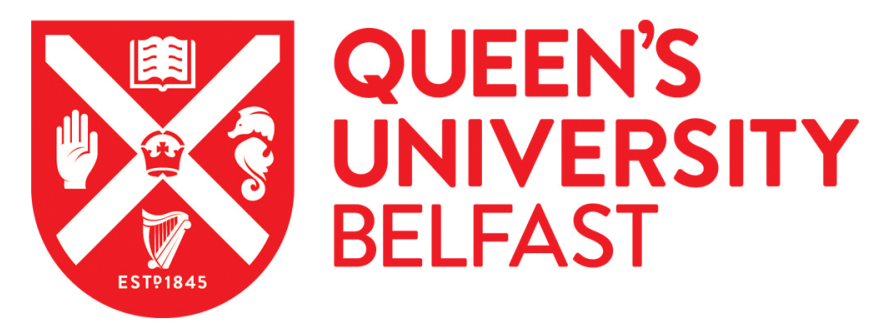

\title{
"I got into a very dark place": addressing the needs of young people leaving care during the Covid-19 pandemic
}

Kelly, B., Walsh, C., Pinkerton, J., \& Toal, A. (2021). "I got into a very dark place": addressing the needs of young people leaving care during the Covid-19 pandemic. Journal of Children's Services.

https://doi.org/10.1108/JCS-05-2021-0022

Published in:

Journal of Children's Services

Document Version:

Peer reviewed version

Queen's University Belfast - Research Portal:

Link to publication record in Queen's University Belfast Research Portal

Publisher rights

Copyright 2021 Emerald.

This is an open access Creative Commons Attribution-NonCommercial License (https://creativecommons.org/licenses/by-nc/4.0/), which permits use, distribution and reproduction for non-commercial purposes, provided the author and source are cited.

\section{General rights}

Copyright for the publications made accessible via the Queen's University Belfast Research Portal is retained by the author(s) and / or other copyright owners and it is a condition of accessing these publications that users recognise and abide by the legal requirements associated with these rights.

Take down policy

The Research Portal is Queen's institutional repository that provides access to Queen's research output. Every effort has been made to ensure that content in the Research Portal does not infringe any person's rights, or applicable UK laws. If you discover content in the Research Portal that you believe breaches copyright or violates any law, please contact openaccess@qub.ac.uk. 
Title: "I got into a very dark place": Addressing the Needs of Young People Leaving Care During the Covid-19 Pandemic.

Authors: Kelly, B., Walsh, C., Pinkerton, J. \& Toal, A.

DOI: https://doi.org/10.1108/JCS-05-2021-0022

\begin{abstract}
Purpose: This paper reports on the findings of a qualitative study that explored the views and experiences of young people leaving care during the first phase of the Covid-19 pandemic in Northern Ireland.
\end{abstract}

Design/methodology/approach: A qualitative approach was adopted involving semistructured interviews with 24 care leavers aged 18-25 years old from across the region. Interviews were conducted remotely online or by telephone and explored young people's lived experiences during the pandemic including their views on the formal support services and how best to provide ongoing for support care leavers during the pandemic.

Findings: Study findings highlight how known adversities for care leavers are exacerbated during the pandemic, having a detrimental impact particularly on their emotional wellbeing. The response of the state as corporate parent in mitigating the impact of the pandemic was found to be inadequate; with a need for need for much clearer communication, transparent and prompt decision making and targeted specialist mental health services. The account given by the young people also highlighted the importance of participation and relationshipbased practice to build on the young people's resilience in the context of high levels of social isolation and limited access to informal support systems.

Originality: This research, based on the views of care experienced young people themselves, is the first study in Northern Ireland to report on the impact of the Covid 19 pandemic on care leaving. As such it makes a contribution to this emerging international field of study and, given the persistence of the pandemic, provides empirical findings and a social justice perspective of ongoing relevance to policy and practice with young people leaving care.

Keywords: leaving care, Covid-19, pandemic, adversity, mental health, relationship-based practice, social justice

\title{
Introduction
}

Since early 2020, the coronavirus (Covid-19) pandemic has significantly impacted on the lives of children and young people across the United Kingdom (UK) and globally. This has 
prompted questions about the management of the pandemic and the impact of related restrictions and service closures on the wellbeing children and young people (Baginsky and Manthorpe, 2020; Child Poverty Action Group, 2021). It is well known from a growing pool of international research that care experienced young people face significant social, health and economic disadvantage (Mann-Feder and Goyette, 2019; Mendes and Snow, 2016, Van Breda and Frimpong-Manso, 2020). It is also internationally recognised that mitigating this disadvantage requires focused state intervention (United Nations 2010) and is an issue of social justice (Mendes et al., 2014). So there has been understandable concern expressed about how care experienced young people have fared during the pandemic across the UK (Canning et al 2020; Coram Voice 2020; Roberts et al 2020; Who Cares? Scotland, 2020). Similar concerns have been expressed in other countries; such as, America (Greeson et al., 2020), Canada (Goyette, 2020), Israel (Lotan et al., 2020), South Africa (MacDonald et al., 2020) and Australia (Rogers et al., 2020). Given what is known about the isolation and mental health challenges that many care leavers experience (Jones, 2019; Kelly et al., 2016; Mendes and Rogers, 2020), a particular cause for concern was that the general social distancing measures adopted in response to the pandemic, along with specific restrictions in health and social care modes of delivery, were increasing the social isolation of care leavers and detrimentally impacting on their mental health.

The research reported here aimed to investigate, primarily from the perspectives of care experienced young people themselves, the extent to which concerns that the pandemic would exacerbate of the social marginalisation of care experienced young people were justified in the particular circumstances of Northern Ireland. The legal context of the Northern Ireland government's 'corporate parent' responsibility for care leavers and its response to their needs in the first phase of the pandemic is set out. This is followed by description and discussion of three key areas of findings from the study which it is suggested lend support to the view that, even in the exceptional context of the pandemic, provision of support and services to care to experienced young people.should be centred on a relationship-based practice perspective rooted in social justice (Mendes et al., 2014; Ruch et al., 2010).

\section{Northern Irish Context}

Health and social care is primarily a devolved matter within each of the jurisdictions in the UK. The current strategy for looked after children in Northern Ireland (NI) states that when a young person becomes looked after by the Health and Social Care Trust (HSCT), the HSCT becomes their corporate parent with responsibility for promoting their wellbeing and welfare. As corporate parent, the HSCT must act "as a parent would be reasonably expected to act" 
assuming "moral as well as legal responsibility for enabling looked after children and young people in its care to experience happy and fulfilling lives" (DoH and DoE, 2021, p. 9). For young people leaving care, the Children (Leaving Care) Act (NI) (2002) and Children (Leaving Care) Regulations (NI) 2005, HSCTs set out clear duties to: maintain contact with youth leaving care; provide aftercare until age 21 or 24 if they are still in further education and training; appoint a Personal Adviser (PA); and develop a pathway plan. In addition, the Children's Services Co-operation Act (NI) 2015 imposes a duty to co-operate in the provision of services for children and young people, thus promoting cross-sector and inter-agency collaboration in child and youth services in NI.

During the first phase of the pandemic the general policy of the NI Government shifted from having people stay at home under lockdown restrictions to maintaining social distance but then had to return to lockdown. Under the Children's Social Care (Coronavirus) (Temporary Modification of Children's Social Care) Regulations (NI) 2020, longer timescales for reviews and for pathway planning was allowed but with no loss of the services available prior to a delayed review regardless of age. Different methods of engagement were also allowed; for example, remote audio-visual communication technology rather than in-person meetings (McFadden et al., 2020). Covid-19 guidance was issued for providers of care for children and young people with a focus on ensuring safety and wellbeing through compliance with public health regulations and efforts to support education (for example, DoH, 2020a). HSCTs were also encouraged to provide additional support for young people in care including therapeutic and mental health services.

A Plan of Cross-Departmental Actions for Vulnerable Children and Young People during the Covid-19 Pandemic Period (DoH 2020b). Some aspects of this plan are particularly relevant to the experiences of care leavers; including actions to address financial hardship and suspension of transitions from child/adolescent to adult mental health services to enable continuity of care. However, care leavers only receive three direct mentions in the plan. The significant role of the voluntary sector to facilitate ongoing engagement with care leavers and enhanced outreach support to care leavers were emphasised. Both the absence of fuller policy direction on services and support for care leavers and the reliance on the voluntary sector, beg questions as to the adequacy of this response given what is known about the needs of care experienced young people.

\section{Pandemic Experience of Care Leavers Elsewhere}

At the time of undertaking the study, only a small body of research was available on the experiences of care leavers in other UK jurisdictions or elsewhere in the world. The available 
research indicated that the needs of care experienced young people were being accentuated during the pandemic (Baginsky and Manthorpe, 2020; Coram Voice, 2020; Who Cares? Scotland, 2020; Goyette et al., 2020; Lotan et al., 2020). In the UK, most of the available research was survey-based and reported concerns about limited informal networks, increased anxiety and reduced contact with formal support services. For example, the NYAS (2020) survey of 230 care leavers in England and Wales reported that the majority of care leavers felt more loneliness and anxiety during lockdown yet had reduced contact with their social worker and personal advisor (PA) and limited access to technology to stay in contact with peers and family. Baginsky and Manthorpe (2020) and Become et al. (2020) also reported that care leavers living alone felt isolated or anxious and those at university were concerned about how to manage disruptions to their studies and living with limited financial incomes.

These themes were reflected in surveys in other countries on the effects of the pandemic on the lives of care leavers. In Israel, Lotan et al.'s (2020) survey of care leavers reported concerns about poverty, limited informal support; and high levels of anxiety and depression. Similarly, Goyette et al.'s (2020) survey of care leavers in Canada found evidence of vulnerabilities to poor housing, mental ill health and unemployment. Greeson et al.'s (2020) survey of care leavers in 32 US States also reported concerns about food poverty, disruptions to education and high levels of depression or anxiety.

A few qualitative studies on the views of care leavers were underway in other parts of the UK at the same time as this NI study (Canning et al., 2020; Roberts et al., 2020). In Scotland, STAF (2020) consultations with professionals, carers and care leavers noted the provision of additional practical support but also highlighted concerns about isolation, digital exclusion, financial insecurity and poor mental health. In Wales, a mixed methods study on the experience of care leavers (Roberts et al., 2020) identified issues relating to accommodation, financial security, education and employment; and isolation.

In summary, the existing literature on youth leaving care during the pandemic, primarily based on survey data, suggested that areas of need well known for care experienced young people (accommodation, finances. education, employment, social networks, emotional and mental health) were being amplified. The study reported here sought to contribute to this emerging pool of empirical work, in particular the very limited body of qualitative research, through the views and experiences of care leavers in $\mathrm{NI}$.

\section{Methodology}


The aim of the study was to explore the impact of Covid-19 on the lives of care leavers in $\mathrm{NI}$ and how these young people had managed during the first lockdown response to the pandemic. The study was interested in the types of support provided to care leavers during the pandemic and how effectively they met their needs in order to inform best practice in advance of a second wave of Covid-19 infections.

Participants were aged between 18 and 25 and entitled to support as a care leaver under the Children (Leaving Care) Act (NI) (2002). Participants were recruited via VOYPIC (Voice of Young People in Care), the NGO supporting children and young people living in and leaving care that commissioned the research. VOYPIC invited all care leavers in contact with their services to participate and interested young people gave consent for their contact details to be shared with the researchers who then arranged a time and place for an interview. The study sought to include young people living in different geographical areas and at various stages of the leaving care journey. The recruitment phase was open during July-September 2020 and, in total, 24 young people took part in interviews during this time. There was good representation across all five HSCT areas with the majority of young people being female $(n=17)$ and having left care $(n=17)$, mostly prior to the pandemic (see Table 1$)$. On average, young people were 20 years old and many were still in contact with their social worker and/or Personal Advisor (PA) as well as a range of other professionals.

\section{Table 1: Participant Demographics [insert table 1 here]}

The fieldwork was undertaken between August and September 2020 when lockdown regulations had been lifted but social distancing restrictions were still in place. Semistructured interviews were conducted with each young person remotely via WhatsApp or telephone. Interview questions were structured around the key themes of: life during the Covid-19 pandemic; experience of formal and informal support; and key messages for service providers on how best to support care leavers during the pandemic. With prior consent, interviews were recorded and transcribed for thematic analysis using the NVivo computer package (Braun and Clarke, 2013).

The researcher who conducted the interviews coded two transcripts and this initial coding framework was then verified and developed in collaboration with other research team members to produce a final coding frame for the analysis of all the other transcripts. The initial findings were presented at a roundtable meeting with 25 social work practitioners and commissioners from statutory leaving care services across $\mathrm{NI}$ followed by a discussion of the implications for policy and practice. 
Ethical approval was secured from the research team's University prior to the commencement of the study with all data being held securely and strictly confidential. This article uses pseudonyms and has removed identifying information to protect the anonymity of participants. The boundaries of confidentiality were explained and all participants verbally confirmed their informed consent at the beginning of each interview. VOYPIC had a staff member designated to provide follow up support and referral for any participant who required further support following their interview.

\section{Findings}

The full study report provides a detailed discussion of the study findings (Kelly et al., 2021). This paper focuses on three central themes: the exacerbation of adversities known to often be experienced by care leavers; the challenge to mental health and emotional wellbeing; and the need to focus on relationship-based practice grounded in a commitment to social justice that facilitates access to required support services (Mendes et al., 2014; Ruch et al., 2010; Ferguson and Woodward, 2009).

\section{Exacerbated Adversities}

Young people's reflections on the challenges they encountered during the pandemic resonated with ongoing themes in the research literature on outcomes for care leavers prior to the pandemic, including: exclusion from employment; difficulties relating to finding appropriate housing and accessing further and higher education; poverty; and poor mental health. A further, key pre-existing issue for care leavers that came to the fore was the digital divide experienced by young people leaving care (Roesch-Marsh et al., 2021; Macdonald et al., 2020; Scottish Care Leavers Covenant Alliance (2020).

\section{The Digital Divide}

As social and professional interactions shifted to online modes of engagement during public health restrictions, care leavers' access to informal and formal support was greatly impacted by their lack of access to technology, limited monies to fund online and telephone activity, and limited skills to engage effectively in digital spaces (McGhee and Roesch-Marsh, 2020; Roesch-Marsh et al., 2021).

Study participants felt there was an assumption that young people would be both digitally competent and digitally accessible. Yet many of our participants struggled with this mode of communication and several reported lack of access to the Internet or having to choose between one online meeting with a professional and having enough mobile data to maintain 
contact with friends or family. These young people indicated that service providers could further explore alternative, non-digital forms of communication, and also provide young people with sufficient financial and technical support engage effectively using virtual models of communication:

"See like Zoom calls... I just hated it... I just go off my data that I would get every month. So, like whenever I was doing Zoom calls and stuff it was draining my data." (Jennifer, 22, left care before Covid-19).

This finding is reflected in studies in other parts of the UK (NYAS, 2020; Roberts et al., 2020; Roesch-Marsh et al., 2020), indicating a need to invest in digital equipment for more care leavers and to provide training on the use of online technology and support to engage effectively on virtual platforms.

\section{Employment Opportunities and Poverty}

A wide range of previous research has reported issues relating to access to employment including the need to develop work-based skills and confidence, the impact of stigmatising employer attitudes, and the importance of inclusive, lifelong models of education that more effectively support care leavers' engagement in employment (Dixon, 2012). Pandemic related restrictions had a significant impact on the labour market with many businesses closing temporarily or permanently, leading to redundancy or furlough conditions as employees cannot attend the workplace (McFadden et al., 2020). Some of the care leavers in this study experienced these changes as they were forced to find new employment, work from home, engage in the furlough scheme, or, in some cases, continue to work in industries (for example, retail or health care) that remained open often on a part-time, contract and low paid basis.

For some who worked in health and social care settings, employment continued but presented a risk of becoming infected with the Covid-19 virus and/or passing it on to vulnerable family members. For one young person, this led to a request by extended family members to leave a stable kinship care arrangement and find alternative housing. This young person understood the request was well intended but had disregarded her own wellbeing and did not allow her sufficient time to prepare for this move emotionally and practically. She left this placement with her belongings in black plastic bin bags that she felt was reminiscent of her experience of coming into care: 
"You know, the typical black bag, and the same thing happened again... even though l'd been there for years." (Una, 23, left care before Covid-19).

Poverty and social deprivation have been reported as dominant features of the lives of young people leaving care (Boddy et al., 2020). Our findings indicate that poverty issues were exacerbated further in the context of the pandemic. The resultant loss of employment or a steady income had a direct impact on care leavers' incomes and their financial security. In addition, as the pandemic continued, the labour market contracted and opportunities to secure employment were severely limited. Many of the young people reported challenges related to managing financially during the pandemic. Practical support from social and community services was very much appreciated, particularly food parcels and vouchers to purchase essential items. However, young people also felt that more of this type of support should be available, especially as the pandemic continued and opportunities to return to employment were limited. Addressing food poverty and the financial challenges that care leavers face is critical as the negative impact of the pandemic on the labour market and shift into recession is likely to continue for some time across the UK (Elliott, 2021).

\section{Accommodation}

Whilst some participants were in secure housing with family members or peers, others were still in the process of moving on from care and finding a suitable home. A few in unstable housing (for example, hostels) or at risk of homelessness were given the opportunity to move to more suitable accommodation on a short-term basis, including temporary hotel stays. Whilst this was a positive shift to a safer and more secure setting, in some cases these temporary arrangements continued for several months despite the need to establish long-term arrangements.

As the pandemic unfolded several young people stayed in their foster care homes or supported accommodation. These opportunities to continue in their current placement offered consistency in support and accommodation, although it meant that transition plans were put on hold indefinitely. There was a perception that, with the onset of Covid-19, it took some time for professionals to align practice with the public health guidance which impacted on some young people's transitional experiences:

“It was... before my $18^{\text {th }}$ and I didn't have a clue where I was going... because no social workers were telling me where I was going... [finally] I was told where I was going, and that was it. I didn't even get really a say or nothing about it like." (Elena, 18, left care during Covid-19). 
Whilst staying in placement under lockdown offered ongoing, secure accommodation, one young person who had a longer than expected stay in residential care felt this had clouded her overall care experience and negatively impacted on the transition process:

"I look back on it and I'm like it was the shittiest, I've been in care... Covid-19 really affected my last kind of memories in the home because I look back and I'll be like ' $f^{\star *} k$ I was under lockdown and the staff didn't do shit with me in my last few months in care'. Whereas if lockdown hadn't have happened I would've been able to do endings with my keyworkers and go out for dinner." (Elena, 18, left care during Covid-19).

Moving on from care into independent living also brought additional challenges as young people transitioned into a new home, often in an unfamiliar area combined with reduced or different format of support:

'You're moving into a world by yourself. ... you'll [usually] have somebody coming out to visit you, but with a pandemic that can't happen. And if you're in lockdown in your new house that could be really lonely." (Una, 23, left care before Covid-19).

\section{Educational Experiences}

Adversities related to access to further and high education have been a persistent theme in the care leaver literature (O'Higgins et al., 2015; Jones, 2019). During the pandemic, young people's engagement in education was impacted in a range of ways. As schools, colleges and universities moved to online or blended learning, young people were expected to attend classes virtually and undertake further independent learning at home. For some care leavers, issues outlined above related to the digital divide severely restricted their access to online learning. Others had limited support at home to enable them to engage effectively with independent learning tasks. Several who were caring for children or living in busy home environments found it difficult to find a private, quiet space to engage in online classes and study:

"I still had to try and do my uni course online, which was pretty stressful with the kids in the house... It was quite difficult." (Brenda, 20, still in care).

There was also uncertainty about examinations and changes to other modes of assessments. In addition, some young people highlighted how their educational 
achievements and successes often went under the radar as graduation ceremonies or celebrations with peers were not permissible.

Finally, the study findings showed that, whilst some young people were very satisfied with support (indeed, several felt they had more support than ever before), others were very dissatisfied with the level of support available to them and reported reductions or cessation of services they depended on. These findings highlight local variations across HSCTs, dependent on where the person lives or which social worker or PA is allocated to their case, indicating inequality in access to services for some young people.

\section{Mental Health and Emotional Wellbeing}

Mental health and emotional wellbeing was a major theme emerging from the findings. Some young people's responses indicated a sense of resilience often based on an understanding that everyone experienced the impact of the pandemic, reflecting the government's message that 'we are all in this together'. Young people described efforts to keep themselves busy, avoid boredom and maintain positive wellbeing:

"Just entertained myself... played games or tried to socialise with the rest of the family". (Brian, 22, still in care).

Several young people indicated that knowing they had overcome past experiences of trauma and challenge offered them some reassurance:

"Care experienced children... are that used to unfamiliar circumstances and things changing that quickly that we can quickly adapt to whatever the new situation is". (Rhianna, 20, left care before Covid-19).

The abundance of free time provided space for young people to pursue hobbies, adopt healthier lifestyles and focus on self-care:

"It made me kind of focus on myself and giving myself time to do the things that I kind of wanted to do that I couldn't do with work and jobs... like pick up my arts and drawing and spend time as a family, like helping with the cooking." (Ellen, 20, left care before Covid-19).

For others, more passive approaches were used to 'get through' the lockdown experience 
"I picked up a bad habit of staying up all night playing the PlayStation and then sleeping all day... it was the only way I seen lockdown getting over quicker." (Phil, 18, left care before Covid-19).

"I can't say I coped with it, but I just say... it passed." (Alex, 18, left care during Covid-19).

However, many young people reported high levels of anxiety, increased low mood or depression:

"My mental health like, the amount of times I would've found myself crying like or cracking up... I literally just was at end's wits... I found myself getting really frustrated easily." (Phoebe, 19, still in care).

There is a growing body of research showing that the mental health of youth in general has deteriorated during the pandemic potentially linked to increased social isolation and lack of access to formal services (Baginsky and Manthorpe, 2020; Lotan et al., 2020). For care leavers who ordinarily require ongoing emotional support (Kelly et al., 2016; Jones, 2019), the pandemic intensified the risk of poor mental health. Those with pre-existing mental health conditions in particular experienced elevated symptoms and psychological distress during the pandemic:

"It just made it a lot worse... because I already had my own struggles. So then when the whole world is struggling it doesn't really help". (Bronagh, 18, left care during Covid-19).

Without access to usual coping strategies and supports, some young people struggled to maintain positive mental health and recognised a deterioration in their emotional wellbeing:

"I noticed that my mental health deteriorated as well because my way of talking to people would be going out for a drive, sitting down, listening to music and then talking" (Elena, 18, left care during Covid-19).

The presence or absence of effective social supports, particularly as time progressed, also had a mediating effect on care leavers' emotional wellbeing. For some young people, merely having someone to talk to would have been welcomed: 
"Because of the period of time I got into a very dark place and I could've done with more support." (Michelle, 18, left care before Covid-19).

Young people described how isolating at home, ongoing stresses linked to the challenges outlined above, fear for their health and uncertainty for their futures all contributed to a deterioration in their mental health. For those with limited or no access to peer, family and other informal supports, their feeling of isolation was stark:

“So obviously like lockdown wasn't the best for me like because I have no family and I live in a one bedroomed flat... The best support I have is friends, but obviously I couldn't see them for a very long time so I did feel quite alone... there wasn't much else to do... I felt like there was no way to sort of escape. It was always just the white walls around me." (Phil, 18, left care before Covid-19).

Some young people, including those with pre-existing mental health diagnoses, had experienced a mental health crises or breakdown during the pandemic. However, many of these young people had experienced delays in medical treatment, postponement of psychological therapies and major difficulties when trying to access services even at times of acute crisis. One young person who had begun a therapeutic programme before the onset of Covid-19 felt that the good progress they had made was greatly reduced when the service had temporarily closed during lockdown:

"I had started a mental health course... and I was finally getting more confident, and then it actually hit me really hard, because like I was doing so well and now I feel like my life's on pause again." (Michelle, 18, left care before Covid-19)

Some described unsuccessful efforts to make telephone contact with mental health services whilst others had made repeated contacts with GPs but did not have an adequate response:

"A few weeks from the lockdown happened my mental health started really deteriorating... and I tried ringing my doctor's.... I was phoning them every other day crying my eyes out uncontrollably because I needed help...And all my doctors were doing was prescribing me more tablets... nothing was put in place, so... I was left basically in the lurch." (Rhianna, 20, left care before Covid-19). 
"And I was like 'I'm really going downhill, and I need some help'...And I told them this for three months, and then... I had a breakdown." (Una, 23, left care before Covid19).

Given the risk of poor mental health outcomes reported previously and highlighted in this research, care leavers require clearer pathways to specialist mental health services and support to access informal and formal sources of support as the pandemic continues.

\section{Relationship-based Practice and Access to Support}

A strong theme in the participant responses was the importance of relationships, informally and formally. Most participants reported feelings of loneliness and social isolation during lockdown and even after these restrictions were eased due to ongoing restrictions on interpersonal contact with peers and family. The cessation of schools/colleges, team sport activities and fitness/leisure opportunities also reduced their access to social relationships and contributed to their sense of loneliness:

"Just being in my room or being in this house all the time was just very difficult... because I couldn't see my friends, I couldn't see my birth family." (Ewan, 18, still in care).

Whilst some young people regarded social isolation as a continuation of their usual life experience, others reported that being thrust into a situation of seclusion had a profound effect:

“That makes me feel terrible, like I couldn't get support from someone. You feel like lonely, and no one is helping you, you know, and... I feel like I am the only one living in the world... life is terrible, struggling". (Alex, 18, left care during Covid-19).

Given this sense of isolation, and the negative effect it had on emotional wellbeing, contact with professionals offering support was crucial including social workers, PAs or counsellors. For some young people during lockdown, these professionals were the only person the young people engaged with and they very much looked forward to these contacts. However, the pandemic led to changes to usual service provision as professionals moved to telephone or online communication and began to prioritise cases for further support or socially distant contact in person in response to public health restrictions and a reduced/changing workforce as staff were isolating or absent due to illness. Several young people enjoyed the opportunity to have in-person contact with professionals primarily via outdoor walks: 
"I enjoyed seeing my social worker pull up in his car, and we would just have a good chat and stuff." (Phil, 18, left care before Covid-19).

However, others did not have these opportunities including those who felt very isolated and in need of face-to-face support:

\begin{abstract}
"It was a very, very, very difficult time for me, because social services couldn't come near me... I had supports over the phone and stuff, but at the time it was very difficult because they didn't know what they were allowed to do... if they were just there as a person that I could physically see as a comfort, they didn't have to come and touch me or come near me... it would've helped me a lot." (Bronagh, 18, left care during Covid19).
\end{abstract}

Young people were aware that services had to be prioritised for those most in need but were unsure how this process of prioritisation was being undertaken or when they could expect access to usual services. Some young people felt that more efforts could be made to communicate with care leavers about these changes to services and to provide clear information about delays or processes of prioritisation.

As contact with key professionals involved in their lives reduced, young people felt their relationship with detrimentally affected. Some care leavers reflected on how previous strong relationships with a social worker or PA who they felt cared for their wellbeing were broken as a result of lack of contact during the pandemic. Some young people were very disappointed that these professionals had made minimal efforts to provide support or maintain their relationship:

"That was the last time I heard from [my social worker] and I've rang him seven times since and l've texted him five times since, and he hasn't texted or contacted me back." (Maxine, 23, left care before Covid-19).

"I found it really difficult... I could've done with a little bit of help from my social worker but obviously he couldn't because of the lockdown restrictions, but I had to do student finance completely on my own. And I got... the wrong amount of money back... So, I felt that I could've got a bit of help with the student finance. My PA was supposed to 
help me with it at the time, but... I found him quite lazy." (Michelle, 18, left care before Covid-19).

Several young people also felt let them down by professionals due to cancelled or missed appointments, often at late notice. One young person who was socially isolated without access to usual peer contact at school or sporting activities, felt disappointment and hurt when his social worker failed to maintain contact with him. His social worker had failed to attend several arranged socially distanced meetings which this young person felt had damaged their relationship and, as a result, when he received his exam results he had noone to share his news with at a key turning point in his life:

“So my results are coming out tomorrow but I won't even be able to tell him, when he's sort of one of the only person in my life who I can tell, and it would've been something that I would've been looking forward to tell him... I feel like the relationship is going to go down because of that. Like l'm just going to be so raging that I can't pick up the phone, and the only sort of adult I have in my life, I can't say to him 'Here look I got this. Are you proud?"' (Phil, 18, left care before COVID-19).

These findings highlight the importance of supporting care leavers to mobilise informal circles of support in their own networks and communities during the pandemic to address high levels of social isolation but also the need to make concerted efforts to maintain relationship-based practice. Young people could benefit from more formal peer support initiatives that could also offer opportunities to contribute to a paid peer workforce programme (Brady et al., 2019). As a fundamental aspect of the corporate parenting role, toung people also needed professionals to show that they cared for their welfare and were still interested in their lives and their transitions during the pandemic, and professionals who were making efforts to communicate and engage with them, in accordance with public health guidance. Young people would have appreciated more socially distanced walks and scheduled, planned, virtual contacts:

"They should be putting slots available... so that I know that they're going to ring me, instead of me trying to get the hold of them and not one of them $f^{* * *}$ ing answering their phones." (Elena, 18, left care during Covid-19).

There is an ongoing challenge for professionals in terms of upholding a relationship-based approach to practice when contact is not in person. Young people acknowledged this 
challenge and preferred face-to-face contact when it was permissible. They feared that the shift to online or telephone contact was becoming a norm rather than a temporary measure and emphasised the important of re-establishing in-person contact promptly. Although participants reported that short-term use of virtual communication and contact was acceptable (though difficult for those who did not have access to technology of funding to support online activity), they did not want this to be a replacement for face-to-face contact in the long-term. Several young people also felt that there were less involved in plans and decisions about their transition from care and would like to see more creative, participatory approaches that were responsive to the changing needs of care leavers during the pandemic.

\section{Discussion}

The study findings show that the Covid-19 pandemic is having a profound impact on the lives of care leavers and services aimed at meeting their needs. Existing adversities, in particular social isolation or loneliness are accentuated as wider society moves in and out of lockdown restrictions and services are retrenched and re-prioritised in response to public health restrictions and workforce pressured. Whilst care leavers suffer the consequences of this, they also demonstrate resilience in the context of the pandemic and make active efforts to promote their own wellbeing and the safety of others.

The familiar challenges for care leavers as they strive to secure appropriate, secure housing and engage in further or higher education and employment are heightened as secure job opportunities are limited in the context of a shrinking economy and education shifts to online modes of delivery and assessment (Elliott, 2021). Many participants described efforts to stay engaged with education and supports delivered online or by telephone but faced a range of challenges, not least the effect of struggling to manage within limited budgets, restricted access to technology, disruptive home environments or house moves as they transitioned form care and dissatisfaction with the level of support available remotely (Roesch-Marsh et al., 2021).

Access to informal supports were also weakened and usual self-care strategies were often unavailable due to restrictions, for example, exercise or team sports, visiting family members or socialising with friends. Within this context, a systemic approach to support is important including assistance to enable contact with informal networks but also formal, structured support. Formal peer mentoring programmes may help to alleviate care leavers' sense of social isolation and have a positive effect on their mental health (Brady et al., 2019). Young 
people moving on from care also need clear and phased transition plans responsive to their changing needs and additional efforts from professionals to maintain their relationship and ensure access to key formal support services (NYAS, 2020).

Whilst a minority of respondents had enjoyed the same or higher levels of support, showing what can be achieved, the majority reported barriers to essential support services, particularly at times of crisis, and inadequate levels of contact and support from professionals that damaged existing relationships. Young people who had regular and sustained contact with a social worker, counsellor or PA who checked on their wellbeing and responded to their needs as they transitioned from care during the pandemic were greatly appreciative of this ongoing support. Others felt let down by professionals who failed to maintain this level of support which often left them feeling uncared for and alone, particularly for those with no other sources of support. These findings lend support to the social justice view that corporate parenting requires not safety net services but flexible and creative, supportive relationships with care leavers even in the context of virtual and socially distanced contact when digital inclusion becomes a crucial challenge (Mendes et al., 2014; Roesch-Marsh et al., 2021; Ruch et al., 2010).

Ingram and Smith (2018) argue that, while relationship-based practice requires a focus on the individual and their emotional world, it is also informed by contextual factors such as poverty, social exclusion and power. Care leavers in this study emphasised the importance of caring and supportive relationships with professionals. However, to fulfil the corporate parenting role, these relationships must be grounded in a firm commitment to social justice (Mendes et al., 2014) that seeks to address the range of adversities experienced by care leavers during the pandemic. Hingley-Jones and Ruch (2016) expressed concern about 'austere professional practice' in the context of financial constraints and pressures on the social care system. Such practice can become emotionally distant and ignore the impact of the retracted support services on service user experiences. Our findings show that these concerns are particularly pertinent for care leavers in the context of the ongoing pandemic. In line with other emerging research on leaving care during the pandemic (Roberts et al (2020), the NI findings give cause for concern about a lack of transparency about the basic level of support and services care leavers can expect irrespective of where they live or the individual professionals or teams they are allocated to. Study participants understood that the pandemic would change how services may be delivered but wanted and had the right to more prompt communication about these changes as they unfolded over time. They needed transparency and involvement in the decisions related to prioritising cases and reestablishing in-person contact with key professionals. Given the findings on the detrimental 
effect of living through the pandemic on the mental health and emotional wellbeing of care leavers, the need for preventive, early intervention and specialist mental health services available for young people experiencing a deterioration in their mental health is also critical.

\section{Conclusion}

The findings from this study enhance our understanding of the views of care leavers and how to deliver a more effective corporate parent response to meeting their needs in this unprecedented context of the pandemic. Although a small-scale study, the Northern Ireland research reported here adds to, and generally reinforces, what is being learnt about the leaving care experience during the pandemic from across the UK (Roberts et al., 2020; Roesch-Marsh et al., 2021). It provides rich insights into the experiences of care leavers in the particular circumstances of the aftermath of the first wave of lockdown when restrictions had eased but were due to be re-introduced in response to concerns about further spread of the virus. Promising practice giving expression to engaged and empowering relationship based work was evidenced but this was only the experience of a minority of participants. Our findings indicate there is still some way to go to provide good enough corporate parenting for these young people. Fundamentally, young people leaving care during the pandemic need empowering support and packages of individualised services that include practical provision (e.g. food parcels and IT equipment), enhanced financial assistance and appropriate mental health support to enhance their capacity for resilience. There is a clear message from young people that they need more consistent, regular contact with professionals who demonstrate a commitment to relationship-based practice that is focused on individualised support but also works at a social structural level to ensure clear routes to formal support when needed (Hingley-Jones and Ruch, 2016). Service systems need to ensure prompt advice and practical support alongside timely, collaborative decision-making, emotional support and assistance at times of crisis. Given the significance of the mental health challenge posed by the pandemic, priority also needs to be given to strengthening access to therapeutic support and comprehensive, inter-agency mental health services for care leavers.

As the pandemic, and government responses to it, continue to develop, so too will the lives of care experienced young people move on. Attention, including further research, needs to be given to the longer-term impact of the pandemic for care leavers, including any lingering effect on young people. In developing appropriate immediate and longer-term responses to the pandemic, service providers need to ensure that any shift towards more limited or remote contact with care leavers is temporary and does not become the norm. Similarly, any new processes for prioritising access to key services under pandemic conditions must not 
become routine. As corporate parents, professionals must give due consideration to the rights of care leavers to be involved in decision-making processes and to have access to services that help mitigate the range of adversities they encounter as they transition from care and enhance their capacity for resilience.

\section{References}

Baginsky, M. and Manthorpe, J. (2020), Managing through Covid-19: the experiences of children's social care in 15 English local authorities, King's College, London.

Become, Stand Alone, NNECL, Unite Foundation and Spectra (2020), 'Supporting careexperienced and estranged students in higher education - responding to Covid-19',

available at: https://www.unitefoundation.co.uk/wp-

content/uploads/2020/04/CovidResponseGroupSurvey2020.pdf (accessed on 28.05.21).

Boddy, J., Bakketeig, E. and Østergaard, J. (2020), 'Navigating precarious times? The experience of young adults who have been in care in Norway, Denmark and

England', Journal of Youth Studies, Vol. 23 No. 3, pp. 291-306.

Brady, B., Dolan, P. and McGregor, C. (2019), Mentoring for Young People in Care and Leaving Care: Theory, Policy and Practice, Routledge, London.

Braun, V. and Clarke, V. (2013), Successful Qualitative Research: A Practical Guide for Beginners, Sage, London.

Canning, R., Taylor, J. and O'Higgins, A. (2020), 'Care in the time of Covid', available at: https://careinthetimeofcovid.org/ (accessed on 28.05.21).

Child Poverty Action Group (2021), Falling Through the Net, CPAG, London.

Coram Voice (2020), Care leavers' well-being during the Covid-19 Pandemic: Key Messages for Leaving Care Workers, Coram Voice, London.

Department of Health (2020a), Covid 19: Guidance for Residential Children's Homes in Northern Ireland, DoH, Belfast.

Department of Health (2020b), Cross-Departmental Actions for Vulnerable Children and Young People during the Covid-19 Pandemic Period (Consultation), DoH, Belfast.

Department of Health and Department of Education (2021), A Life Deserved: "Caring" For Children \& Young People In Northern Ireland, DoH and DoE: Belfast.

Dixon, J. (2012), 'Obstacles to participation in education, employment and training for young people leaving care', Social Work and Social Sciences Review, Vol 13 No. 2, pp. 18- 34. Elliott, L. (2021), 'Fears of UK double-dip recession rise as activity slumps in Covid-19 lockdown', The Guardian, 22 January, available at:

https://www.theguardian.com/business/2021/jan/22/uk-manufacturing-and-services-activityslump-to-eight-month-low (accessed on 28.05.21). 
Ferguson, I. and Woodward, R. (2009), Radical Social Work in Practice - Making a difference, Policy Press, Bristol.

Goyette, M., Blanchet, A. and Bellot, C. (2020), The Covid-19 pandemic and needs of youth who leave care, University of Public Administration, Quebec.

Greeson, J., Jaffee, S. and Wasch, S. (2020), The Experiences of foster youth during Covid19, Field Centre for Children's Policy, Practice and Research, Philadelphia.

Hingley-Jones, H. and Ruch, G. (2016) 'Stumbling through? Relationship-based social work practice in austere times', Journal of Social Work Practice, Vol. 30 No. 3, pp. 235-248.

Kelly, B., McShane, T., Davidson, G., Pinkerton, J., Gilligan, E. and Webb, P. (2016), Transitions and outcomes for care leavers with mental health and/or intellectual disabilities: Final report, QUB, Belfast.

Kelly, B., Walsh, C., Pinkerton, J. and Toal., A. (2020), "I already had my own struggles. So then, when the whole world is struggling, it doesn't really help": The Voices of Young People Leaving Care During Covid-19 in Northern Ireland, QUB \& VOYPIC, Belfast.

Ingram, R. and Smith, M. (2018), Relationship-based Practice: Emergent themes in social work literature, Insight 41- A Series of Evidence Summaries, IRISS, Glasgow.

O'Higgins, A,, Sebba, J. and Luke, N. (2015), What is the relationship between being in care and the educational outcomes of children? An international systematic review, Rees Centre, Oxford.

Jones, L. (2019), 'Remaining in foster care after age 18 and youth outcomes at the transition to adulthood: A review', Families in Society: The Journal of Contemporary Social Services, Vol. 100 No. 3, pp. 260-81.

Lotan, H., Refaeli, T. and Meital-Schwartz, T. (2020), Care leavers versus at-risk youth in the community during Covid-19 outbreak in Israel, available at:

file://C:/Users/3040347/Downloads/Young\%20adults\%20at\%20risk\%20during\%20Covid19\%20outbreak\%20in\%20lsrael.pdf (accessed on 28.05.21).

MacDonald, M., Dellis, A., Mathews, S. and Marco, J. (2020) 'Implementing E-mentoring with care-experienced youth under "lock-down" - a South African experience', Journal of Children's Services, Vol. 15 No. 4, pp. 253-258.

Mann-Feder, V. R. and Goyette, M. (2019), Leaving Care and the Transition to Adulthood: International Contributions to Theory, Research and Practice, Oxford University Press, New York.

McFadden, P., Nicholl, P., Mackle, D. and Ross, J. (2020), NI Report for IASSW Country Report on Social Work and COVID-19 until 30th June 2020, University of Ulster, Derry. McGhee, K and Roesch-Marsh, A. (2020), Bridging the digital divide for care experienced young people in Scotland: If not now, when? CELCIS / Scottish Care Leavers Covenant, Strathclyde. 
Mendes, P. and Snow, P. (2016) (Eds.), Young People Transitioning from Out-of-Home Care: International Research, Policy and Practice. Palgrave Macmillan, London.

Mendes, P., Pinkerton, J. and Munro, E. (2014) 'Young People Transitioning from Out-of-home Care: An Issue of Social Justice', Australian Social Work, Vol. 67 No. 1, pp. 1-4.

NYAS (2020), 'Young lives in lockdown: NYAS' survey of care-experienced children and young people during Covid-19', available at https://www.nyas.net/wp-content/uploads/NYASCoronavirus-Survey-Report-Young-Lives-in-Lockdown-May-2020.pdf (accessed on 28.05.21).

Roberts, L., Rees, A., Bayfield, H., Corliss, C., Diaz, C., Mannay, D. and Vaughan, R. (2020), Young People Leaving Care, Practitioners and the Coronavirus (Covid-19) Pandemic: Experiences, Support, and Lessons for the Future, CASCADE, Cardiff University and Voices from Care CRYMU, Cardiff.

Roesch-Marsh, A., McGhee, K and Gillon. F. (2021), The digital divide: The impact on the rights of care leavers in Scotland, CELCIS, Strathclyde.

Rogers, J., Mendes, P. and Thomas, I. (2020), 'Care leavers and COVID-19: A time for even greater state and community responsibility ABC's Religion and Ethics portal', available at: https://www.abc.net.au/religion/dont-forget-care-leavers-during-the-coronaviruscrisis/12152820 (accessed on 28.05.21).

Ruch, G., Turney, D. and Ward, A. (Eds.) (2010), Relationship-Based Social Work: Getting to the Heart Of Practice, Jessica Kingsley, London.

Scottish Care Leavers Covenant Alliance (2020), 'Collaborative Voice' Briefing - The challenge of 2020: Supporting care leavers in Scotland during the pandemic and beyond, Scottish Care Leavers Covenant Alliance, Scotland.

STAF (2020), 'Covid-19 impact on care leavers highlights need to build back better', available at: https://www.staf.scot/Handlers/Download.ashx?IDMF=9822be5f-8855-4e7dbe08-ab380962f4ab (accessed: 28.05.21).

United Nations (2010), Guidelines for the Alternative Care of Children, United Nations General Assembly, Geneva, Switzerland.

Van Breda, A. and Frimpong-Manso, K. (Eds) (2020), 'Leaving Care in Africa', Emerging Adulthood, Vol. 8 No. 1, pp. 3-5.

Who Cares? Scotland (2020), The Impact of Covid-19 on Scotland's Care Experienced Community, Who Cares? Scotland, Glasgow. 